\title{
BASILAR MIGRAINE PRESENTING AS ALEXIA
}

\author{
Adarsh A. K1, Sajeeth Kumar K. $G^{2}$
}

1 Junior Resident, Department of Medicine, Government Medical College, Kozhikode.

2Professor, Department of Medicine, Government Medical College, Kozhikode.

HOW TO CITE THIS ARTICLE: Adarsh AK, Kumar SKG. Basilar migraine presenting as alexia. J. Evolution Med. Dent. Sci. 2018;7(09):1166-1167, DOI: 10.14260/jemds/2018/265

\section{PRESENTATION OF CASE}

A 24 years old male, B Arch student from Kozhikode presented with sudden onset neck pain and occipital headache of 3 days duration associated with vertigo, followed by difficulty in reading for 2 days and transient forgetfulness. There was no difficulty in writing and comprehension of spoken words, no difficulty in calculations, no h/o vomiting, fever, visual symptoms, double vision, deviation of angle of mouth, dysarthria, weakness of limbs, sensory symptoms, seizures, urinary incontinence, impairment in coordination. No history of trauma. No history of breathlessness, chest pain, syncope, palpitations, cough, dysuria, oliguria, high coloured urine, abdominal pain, jaundice, loose stools or constipation. He has history of unilateral headache in past- 3 episodes in 1 year-lasting for a few hours, not associated with any other symptoms and relieved with analgesics, suggestive of migraine. No h/o diabetes, hypertension, bronchial asthma, pulmonary tuberculosis, epilepsy or heart disease in the past. No history of trauma or surgery in the past. He is a nonvegetarian. He has normal bowel and bladder habits and no addictions or any promiscuous behaviour.

On examination, he is conscious, oriented, cooperative; moderately built and moderately nourished, no pallor, icterus, cyanosis, clubbing, significant lymphadenopathy or oedema, no thyroidomegaly, clinically euthyroid, normal skin, hair and nails. Pulse rate-74/minute, regular, normal volume and character; blood pressure-120/80 mm Hg; afebrile; respiratory rate-16/ minute. Nervous system examination revealed inability to read letters and words with preserved comprehension, writing, word output and naming, normal intelligence, no focal neurologic deficit or any signs of meningeal irritation. Cardiovascular system showed normal heart sounds, no murmurs, chest -normal vesicular breath sounds, no added sounds, abdomen examination was also within normal limits.

\section{DIFFERENTIAL DIAGNOSIS}

A diagnosis of pure alexia was kept. The aetiologies considered were cerebrovascular accident or cerebral venous thrombosis. A possibility of vertebrobasilar insufficiency/ vertebral artery dissection was also considered. Basilar migraine is also considered as the patient had previous history of migraine attacks and he was investigated.

'Financial or Other Competing Interest': None.

Submission 30-12-2017, Peer Review 07-02-2018,

Acceptance 14-02-2018, Published 26-02-2018.

Corresponding Author:

Dr. Adarsh A. K

Junior Resident,

Department of Medicine,

Government Medical College,

Kozhikode.

E-mail:aakcmc@yahoo.com

DOI: $10.14260 /$ jemds $/ 2018 / 265$

(c) $($ ) $(5)$
His investigations revealed haemoglobin $13.8 \mathrm{~g} / \mathrm{dl}$ with a mean corpuscular volume of 86.4 , red cell distribution width 13.4 , total leucocyte count 7200 with differential neutrophil $68 \%$, lymphocytes $28 \%$ and mixed cells $4 \%$, platelet count of 2.98 lakh, erythrocyte sedimentation rate $18 \mathrm{~mm}$, random blood sugar $86 \mathrm{mg} / \mathrm{dl}$, blood urea $24 \mathrm{mg} / \mathrm{dl}$, creatinine 0.8 $\mathrm{mg} / \mathrm{dl}$, serum sodium 138 meq, potassium 3.9 meq, calcium 9.2 meq, magnesium 3.7 meq, phosphorus 4.2 meq, uric acid $5.3 \mathrm{mg} / \mathrm{dl}$, total bilirubin $1 \mathrm{mg} / \mathrm{dl}$, conjugated bilirubin 0.3 $\mathrm{mg} / \mathrm{dl}$, serum protein $7.2 \mathrm{mg} / \mathrm{dl}$, albumin $3.9 \mathrm{mg} / \mathrm{dl}$, alanine aminotransferase $34 \mathrm{U}$, aspartate aminotransferase $42 \mathrm{U}$ and alkaline phosphatase $98 \mathrm{U}$. Urine routine was normal. Prothrombin time was also normal.

CT Brain-Normal, Chest X Ray-Normal, ECG-Normal, Echocardiogram-Normal.

An MRI brain with MR angiogram and venogram was done which did not reveal any infarct/ bleed/ demyelination or any mass lesion.

\section{CLINICAL DIAGNOSIS}

As the patient's symptoms subsided after 3 days with resolution of headache by symptomatic treatment and no definite lesions were obtained after imaging, we arrived at a possibility of pure alexia due to basilar migraine which occurs as a rare reversible complication of migraine attacks [1]. He was completely normal at discharge and was discharged with migraine prophylaxis.

\section{PATHOLOGICAL DISCUSSION}

Patients with pure alexia can write, but not read. Comprehension and word output remain intact [2]. Lesions occur in the left occipital lobe and extend to the splenium of the corpus callosum (e.g. left posterior cerebral artery occlusion or mass lesion) [3]. A right visual field defect may be present. Visual information reaches the left visual field but pathways that allow interpretation of written language from the left visual field are interrupted.

Basilar-type migraine (BTM) is a rare form of migraine with aura. Here, the primary signs and symptoms are referable to either the brainstem or both cerebral hemispheres without any weakness. It may present with vertigo, tinnitus, diplopia, dysarthria, etc. Other manifestations include bilateral visual symptoms, paraesthesias, hypacusis and decreased level of consciousness.

Basilar migraine can present as pure alexia without agraphia and transient memory disturbance. It is reversible and subsides with relief of headache. Our patient had history of migraine in the past and present history is suggestive of a vascular cause for the neurologic deficit. However, MR imaging was normal which ruled out infarct, bleed, mass lesion or demyelination. Alexia in migraine is probably due to vasospasm which may be demonstrated by angiography; neuronal metabolic changes are also implicated. It may 
precede or follow the attack of migraine[4]. In the former situation, it is considered as a migraine aura. Migraine aura consists of spells of reversible focal neurologic dysfunction which is explained by theory of cortical spreading depression.

\section{DISCUSSION OF TREATMENT}

Our patient was treated with paracetamol, naproxen and flunarizine. His headache subsided, and he was able to read thereafter. Our patient is on follow up now, he is on propranolol for migraine prophylaxis. Other drugs that may be used for prophylaxis are topiramate and sodium valproate. Till last follow up visit, he did not have further similar episodes.

\section{FINAL DIAGNOSIS}

Pure alexia without agraphia due to basilar migraine in a 24 years old male.

\section{REFERENCES}

[1] Bigley GK, Sharp FR. Reversible alexia without agraphia due to migraine. Arch Neurol 1983;40(2):114-5.

[2] Little RD, Goldstein JL. Alexia without agraphia in a child with acute disseminated encephalomyelitis. Neurology 2006;67(4):725.

[3] Mao-Draayer Y, Panitch H. Alexia without agraphia in multiple sclerosis: case report with magnetic resonance imaging localization. Mult Scler 2004;10(6):705-7.

[4] Suhaib 0, Vaughn A. Alexia with agraphia as a rare presentation of migraine. Neurology 2015;84(14 Suppl). 